\title{
STUDENTS' TOURISM COMPETENCES IN INTERNSHIPS BY GEOGRAPHIC VARIABLES
}

\author{
J. Sales-Zaguirre ${ }^{1}$, R. Ferreras-Garcia² ${ }^{2}$ E. Serradell-López ${ }^{2}$ \\ ${ }^{1}$ Universitat Ramon Llull (SPAIN) \\ ${ }^{2}$ Universitat Oberta de Catalunya (SPAIN)
}

\begin{abstract}
The aim of this study is to compare the achievement of students' tourism competences when developing internships depending on geographic variables.

In order to analyse these effects, we present an empirical study to know the relationship between geographical variables and internships in achieving tourism competences. We will conduct the analysis from the point of view of the real achievement of these skills. In this sense, we use data obtained from 389 questionnaires distributed among students' supervisors of the Bachelor Degree in Tourism and Hospitality Management at the Universitat Ramon Llull. The questionnaires measure the students' real competences achievement by means of the supervisor's evaluation.
\end{abstract}

To sum up, we can point out that the geographic area is an important variable to take into account when participating in internship programs in terms of achievement of tourism competences.

Keywords: Internship, competences, Higher education, tourism, geographic.

\section{INTRODUCTION}

In the academic world, there are as many definitions of the concept of competence as there are studies that have been undertaken on this subject. Barraycoa and Lasaga (2009) [1] warn us that exploring the concept of competence is a complex, arduous task.

The goal of educational programmes is to foster competences. As González and Wagenaar (2006) [2] point out, competences are described as reference points for the design and assessment of programmes of studies.

The scientific literature on the study of competences and their relationship with education is extensive and the number of studies has increased considerably in recent years (for example, Ferreras-Garcia et al., 2019 [3]; Fitó-Bertran et al., 2014 [4]; Tchibozo, 2011 [5]; Van Der Linden and Mendonça, 2006 [6]).

The tourism industry has become one of the sectors with the most job opportunities worldwide (Lockwood and Medlik, 2003 [7]). Despite the large number of studies on the topic, there is no consensus on which competences are most important for the tourism and hotel industry (Baum, 2002 [8]; Munar and Montaño, 2009 [9]).

One of the main strategies for most universities is to embed employability throughout the whole curriculum. Therefore, specific modules such us internships have been introduced in different Bachelors Degree, such as for example the Bachelor Degree in Tourism and Hospitality Management.

Internships excel at involving all three stakeholders: the students, the company supervisors and the academic team. This involvement is always around the learning and evaluation of competences. Empowering the companys' supervisors in the deployment of the assessment increases the level of commitment towards the internships.

Internships have the aim to bring into play, in an integrated manner, the knowledge and competences that the students have acquired during the degree course, and to accredit that the students have the skills that they will need in the professional environment. Internships act as a bridging tool to bring the professional world closer to the learning competences of the future employees in the tourism and hospitality sector (Raybould and Wilkins, 2005 [10]; Rae, 2007 [11]). Mareque and De Prada (2018) [12] and Molina et al. (2007) [13] agree that undertaking internships reinforces the theoretical and practical training received in universities and enables students to develop professional competences in the labour market. 
Cooperation between universities and industry is vital to ensure that the needs of both educators and industry are covered (Donina and Luka, 2014 [14]).

Our main aim is to analyse whether or not there are differences in how students achieve tourism competences when participating in internships, comparing the internship typology (national or international) and the geographic area (Europe, North America, South America, Africa and Asia). To analyse this goal, we will ask the following research questions:

RQ1: Are there significant differences in the students' tourism competences when developing internships depending on the internship typology?

RQ2: Are there significant differences in the students' tourism competences when developing internships depending on the geographic area?

\section{METHODOLOGY}

\subsection{Work-based Learning}

The Work-based learning subject (WBL) is a 30-credit course in the programme of studies for the Bachelor Degree in Tourism and Hospitality Management at the School of Tourism and Hospitality Management Sant Ignasi (HTSI) that the student must take to complete the degree and which is closely tied with the other subjects studied during the programme.

The WBL seeks to put into practice the academic progress and the competences developed at the previous semesters by students. It allows students to reflect upon the application of the competences in a real professional context and is the perfect setting to obtain individual feedback of their professional competences, level of expertise and improvement areas.

\subsection{Research Strategy and Design}

Because of the nature of our research and in order to attain the purpose pursued by this study, we have adopted a positivist research philosophy. Applying this research methodology, we will be able to test the competences that we have defined against the primary sources and accept or reject the research hypotheses proposed on the basis of the data obtained.

We will use a deductive research approach, consisting of a structured methodology which develops theories from existing knowledge in order to test them empirically against quantitative data.

In order to answer the research questions, we will perform a quantitative analysis, collecting quantitative data about the target population and analysing this data quantitatively with the help of descriptive, inferential and multivariant statistics.

In order to analyse these effects we present an empirical study to know the relationship between geographic situation and internships in achieving tourism competences. We will conduct the analysis from the point of view of the real achievement of these skills by means of the supervisor's evaluation. In this sense, we use data from questionnaires distributed among students' supervisors during the academic years between 2011 and 2017.

As we have mentioned, the information about the students' competences was compiled from a questionnaire, using a non-comparative ordinal four-point scale (in which 1 meant "Disagree strongly" and 4 meant "Agree strongly"). This is a commonly used method in this type of research. The questionnaires measure the students' real competences achievement according to the evaluation of their supervisors. A total of 389 students' evaluations of the Bachelor Degree in Tourism and Hospitality Management at the Universitat Ramon Llull were obtained.

\section{RESULTS}

\subsection{Variables}

The competences included in the Bachelor in Tourism and Hospitality Management were decided creating a commission with other universities in the tourism and hospitality field, on a national and international level and contrasted with the industry. However, the competences deemed appropriate for the specific Work-based learning module were those close to transferable skills. 
The competences were divided into four blocks (Table 1). The first block corresponded to basic competences, the second to personal cross-disciplinary competences, the third to social and relationship cross-disciplinary competences and the fourth to management cross-disciplinary competences.

The statistical techniques used to answer the research questions were Student's $t$ test and ANOVA test for independent samples.

Table 1. Variables

Basic competences

B1. Acquire, understand and structure knowledge

B2. Apply knowledge

B3. Search for and manage information in order to solve problems, transmit reflective judgements and/or make decisions

B4. Communicate information and/or knowledge in one's mother tongue, as well as in at least two foreign languages

B5. Learn autonomously and continuously

Personal cross-disciplinary competences

G1. A commitment to ethics

G2. Orientation towards achievement

G3. Initiative and entrepreneurial spirit

G4. Self-knowledge and emotional self-control

G5. Flexibility/adaptability and self-confidence

Social and relationship cross-disciplinary competences

G6. Empathy and interpersonal comprehension

G7.Team work and collaboration

G8. Sensitivity and intercultural awareness

G9. Service orientation

Management cross-disciplinary competences

G10. Planning and organization

G11. Development of organizational culture

G12. Personal development

G13. Change Management

G14. Leadership

\subsection{Internships Typology}

As regards the Typology segmentation variable, the data were analyzed by differentiating between the internships developed in national territory or on the contrary it were done abroad.

The results showed that, for most competences, the competences' achievement of the students who have done national internships is greater than the achievement held by those who have done international internships with values over 3.8, except for the competence related to initiative and entrepreneurship. The skills best achieved are those related to ethics, planning and organization, selfknowledge and emotional self-control and leadership, all of them over 3.8 points. While the skill worst achieved is the one related to initiative and entrepreneurship, which moreover is the only one in which international students have a better achievement.

When we analyse if the differences are significant, the level of significance of the t-Student test leads us to accept the null hypothesis of no significant differences between the means of basic competences, with a risk $\alpha=0.05$. However, competences related to ethics, self-knowledge and emotional self-control, empathy and interpersonal comprehension, sensitivity and intercultural awareness, development of organizational culture and change management show significant differences between the means of the national and international internships. 
It can be inferred from these results, as a general rule, that developing internships in national territory entails a greater achievement of competences, therefore it seems that this variable affects the level of competences.

\subsection{Continent}

As regards the Continent segmentation variable, the data were analyzed by differentiating between the internships developed in Africa, North America, South America, Asia and Europe.

If we analyze the development of the competences according to the continent where students develop their internships, we note that the means of attainment of the highest competences are in North America and Asia, specifically for 15 of the 19 competences. These rates are always higher than Europe.

If we analyse the significance of these differences, the ANOVA test show that there is a large number of variables that show significant differences with a risk $\alpha=0.05$ in the means depending on where the internships are carried out. Specifically, the competences related to communication, attitude and social and relationship competences.

Thus, we can deduce that developing internships in North America and Asia implies a superior students' competences achievement with regard to those that develop them in Europe.

\section{CONCLUSIONS}

In the introduction of this paper, we highlighted the dearth of studies on this subject. This study has enabled us to broaden knowledge on the attainment of competences within the framework of internships in the field of tourism when we segment by the geographic variables.

With the reforms involved in the Bologna Process, studies on skills and their relationship with the teaching/learning process have risen considerably. Thus, we have seen that there are many experiences in the scientific literature addressed to the study of competences, in general, and their relationship to education. However, to our knowledge, there are no studies that analyse the achievement of tourism competences by students when participating in internships, and more specifically, the potential influence of geographic variables.

Our main aim is to analyse whether or not there are differences in how students involved in academic internships achieve tourism skills taking into account geographical variables.

The results show that, the students' acquisition of tourism skills is superior for students developing national internships, except for competences related to initiative and entrepreneurial spirit. We haven't found significant differences in the mean values of the basic competences, however we have found significant differences for generic competences related to ethics, self-knowledge and emotional selfcontrol, empathy and interpersonal comprehension, sensitivity and intercultural awareness, development of organizational culture and change management.

Regarding the continent variable, the obtained results show that North America and Asia have the highest values for most of the competences. Moreover, these values are always higher than in Europe. In this case, when comparing the area where students develop internships we obtain significant differences in the mean values of a large number of competences, specifically competences related to communication, attitude and social and relationship skills.

From these results we can conclude that the geographic area is an important variable to take into account when participating in internship programs in terms of achievement of tourism competences. Thus, depending on the kind of skills the students want to develop or improve, the University's Internship and Mobility Service should recommend a geographical area or another.

The aim of our study is fully justified because of the consensus on the importance of competences in the academic and professional world. We also wish to contribute knowledge and to try, resolve and study some of the research that has not been previously analysed in depth, in the absence of any previous study with the same characteristics. 


\section{REFERENCES}

[1] J. Barraycoa, O. Lasaga, Competencias e inserción laboral: un análisis de la empleabilidad de los recién licenciados en ADE y Económicas. Barcelona: CEU Ediciones, 2009.

[2] J. González, R. Wagenaar, "Tuning Educational Structures in Europe. La contribución de las universidades al proceso de Bolonia". http://www.deustopublicaciones.es/deusto/index.php/en/tuning-en/tuning-bolonia-en, 2006.

[3] R. Ferreras-Garcia, A.B. Hernández-Lara, E. Serradell-López, "Entrepreneurial competences in a higher education business plan course, " Education + Training, doi.org/10.1108/ET-04-2018-0090, 2019.

[4] À. Fitó-Bertran, A.B. Hernández-Lara, E. Serradell-López, "Comparing student competences in a face-to-face and online business game," Computers in Human Behavior, vol. 30, pp. 452-459, 2014.

[5] G. Tchibozo, "Emergence and outlook of competence-based education in European education systems: An overview," Educational Studies, vol. 4, no. 3, pp. 193-205, 2011.

[6] J. Van Der Linden, M. Mendonça, "From competence-based teaching to competence-based learning: The case of generic competences in the faculty or education at the Eduardo Mondlane University in Mozambique," Perspectives in Education, vol. 24, no. 3, pp. 37-51, 2006.

[7] A. Lockwood, S. Medlik, Tourism and hospitality in $21 \mathrm{~h}$ century. Oxford: Butterworth-Heinemann Publication, 2003.

[8] T. Baum, "Skills and training for the hospitality sector: A review of issues," Journal of Vocational Education and Training, vol. 54, no. 3, pp. 343-364, 2002.

[9] A.M. Munar, J.J. Montaño, "Generic competences and tourism graduates," Journal of Hospitality, Leisure, Sports and Tourism Education, vol. 8, no. 1, pp. 70-84, 2009.

[10] M. Raybould, H. Wilkins, "Over qualified and under experienced: Turning graduates into hospitality managers," International Journal of Contemporary Hospitality Management, vol. 17, no. 3, pp. 203-216, 2005.

[11] D. Rae, "Connecting enterprise and graduate employability: challenges to the higher education culture and curriculum?," Education + Training, vol. 49, no. 8/9, pp. 605-619, 2007.

[12] M. Mareque, E. De Prada, "Evaluación de las competencias profesionales a través de las prácticas externas: incidencia de la creatividad," Revista de Investigación Educativa, vol. 36, no. 1, pp. 203-219, 2018.

[13] E. Molina, A. Bolívar, A. Burgos, "Mejorar el practicum de pedagogía. Aportaciones desde la investigación," Revista de investigación educativa, vol. 25, no. 2, pp. 443-461, 2007.

[14] A. Donina, I. Luka, "The compliance of tourism education with industry needs in Latvia," European Journal of Tourism, Hospitality and Recreation, vol. 5, no. 3, pp. 91-120, 2014. 